\title{
Hands-On Parent Empowerment (HOPE) Project: Comparing Implementation in Social Service Centres and Preschools
}

\author{
Cynthia Leung ${ }^{1}$, Sandra K. M. Tsang ${ }^{2}$, Suzanne Dean ${ }^{3}$ \\ ${ }^{1}$ Department of Applied Social Sciences, The Hong Kong Polytechnic University, Hong Kong, China \\ ${ }^{2}$ Department of Social Work and Social Administration, The University of Hong Kong, Hong Kong, China \\ ${ }^{3}$ School of Psychology, Psychiatry and Psychological Medicine, Monash University, Melbourne, Australia \\ Email: ssleung@polyu.edu.hk
}

Received July 10 $0^{\text {th }}, 2012$; revised August $15^{\text {th }}, 2012$; accepted August $22^{\text {nd }}, 2012$

\begin{abstract}
This project examined the effectiveness and implementation of an early intervention program for children from new immigrant families in Hong Kong in two delivery settings, preschools and social services centres. Participants included 141 new immigrant mothers with preschool children, from 13 preschools and two social services centres. The preschool participants were randomized into an intervention group (30-session HOPE program) and a comparison group (six-session program) at the preschool level, while participants from the two social services centres attended the 30-session HOPE program. Results indicated that the HOPE participants in preschools and social services centres reported lower post-intervention child behavior problem scores than the comparison group. Preschool HOPE participants reported higher post-intervention social support than the social services HOPE participants and comparison group participants. Qualitative information from preschool principals and centre supervisors indicated different dynamics within the two settings. Implications and suggestions for service delivery were discussed.
\end{abstract}

Keywords: Child Development; School Readiness; Early Intervention; Effective Intervention; Preschoolers

\section{Introduction}

It is recognized that inappropriate parenting is one of the significant determinants of child developmental problems such as child behavior problems. Parent training for parents of young children has the potential to prevent the occurrence of future developmental problems such as behavior or conduct problems (Barlow \& Parons, 2005).

Though the effectiveness of parent training programs as an early intervention strategy is well recognized, Shriver and Allen (2008) point out that the context of delivery is an important consideration in the delivery of parenting programs. Practitioners need to be aware of contextual variables which might influence the effectiveness and integrity of the program. An understanding of these contextual variables can provide important information to encourage participation and to enhance effectiveness.

In a meta-analysis on the effectiveness of parenting programs, it was concluded that offering training in the community might reduce psychological and logistic barriers to attendance which might influence outcome (Reyno \& McGrath, 2006). In an earlier study, Cunningham, Brenner and Boyle (1996) found that economically-disadvantaged families were more likely to complete parent training programs in community-based settings than in clinic-based settings. Gross and Grady (2006) pointed out that administrative support for parenting programs was important and staff would need to be enthusiastic about the program to encourage parents to attend. This would be more likely to happen where the mission of the organization was the same as that of the parent training program.

Non-profit making child/family services agencies are common community service providers providing parent training
(Kohl, Schurer, \& Bellamy, 2010). Apart from child/family services agencies, Gross and Grady (2006) claimed that preschools offered the greatest potential for providing access to parents. Preschools are likely to be good partners as their primary goal of promoting child development is consistent with those of parent training programs as a form of early intervention for child developmental problems. Staff will probably see parent training as enhancing the goals of the preschool. Their support and encouragement are vital for motivating parent participation and attendance.

From the perspective of help-seeking behavior, knowledge/ awareness of available services and perceived accessibility of service are important considerations (Leong \& Lau, 2001). It is probably easier for parents to gain knowledge of parent training programs organized by/co-organized with preschools and it is likely that they would consider such programs accessible.

On the other hand, compared with preschools where intensive individual treatment protocols may not be viable (Shriver \& Allen, 2006), social services centres have the advantage of individualized services for families who need more intensive support, and they are in a better position to deal with other family issues such as marital or financial problems. One disadvantage of social service centre is that it may be seen as a place for people with problems and there is a stigmatization effect (Leong \& Lau, 2001) which might adversely affect participation in the first place.

\section{The Hong Kong Situation}

In Hong Kong, parent training has become more popular since the 1980s. They are mainly provided by the education, social service and health sectors (Tsang \& Leung, 2005). 
Within the health sector, services are mainly provided by nurses or health professionals (Leung, Ip, Tso, \& Leung, 2003). In social services agencies, the training is usually conducted by social workers (Tsang \& Leung, 2005). Within government funded/subsidized primary and secondary school settings, the training may be provided by student guidance personnel, or school social workers, and sometimes through outsource service by social workers in social service agencies. However, though the preschool attendance rate is close to $90 \%$ (Census and Statistics Department, 2007a), provision of parent training in preschools is often limited by resource constraints because the Hong Kong government does not fund free preschool education (Rao \& Li, 2009).

Though there is information on the effectiveness of parent training in the Hong Kong context, there is no Hong Kong data as to whether the context of delivery might influence parent participation or program effectiveness in early intervention programs such as parent training programs. The present study aimed to investigate the influence of context of delivery on the effectiveness of the HOPE program. The effectiveness of the HOPE program in a preschool setting has already been reported (Leung, Tsang, \& Dean, 2011). The current study made use of additional unpublished data from the HOPE study to investigate the influence of context of delivery on program effectiveness. The HOPE program was designed as an early intervention program for new immigrant parents from mainland China with preschool children. It consisted of 30 weekly sessions on language and reading, preschool concepts, and behavior management techniques. The program details can be found in Leung, Tsang, Dean, \& Chow (2009).

As part of the design to evaluate the program, preschools which were willing to participate were randomized into the intervention arm (HOPE program) and comparison arm, with the preschool as the unit of randomization to avoid feelings of inequality amongst the parents should they be assigned to intervention or control groups in the same school, or experimental diffusion. Two social service centres expressed interest in the HOPE program, after hearing about the program from the researchers. As they were not able to recruit a sufficient number of participants to randomize them into intervention and control group within centres, all participants in these two centres were offered the HOPE program. This situation offered the opportunity to adopt a quasi-experimental design to compare the delivery and effectiveness of a parent training program between preschools and social services centres, which are set up for different purposes with different target groups. It is recognized that this is post hoc data, but the information may provide insight for early intervention strategies and services providers as well as directions for future research.

\section{Method}

\section{Participants}

The participants included 141 Chinese new immigrant parents fulfilling the inclusion and exclusion criteria. The inclusion criteria required was at least one parent being a new Chinese immigrant (immigrant from mainland China who has resided in Hong Kong for less than seven years, which is the official definition of a new immigrant in Hong Kong); the parent and the target child being normally resident in Hong Kong; and the target child being between 3 and 5 years of age and attending preschools in Hong Kong. The exclusion criteria included chil- dren with major developmental problems, or parents with history of domestic violence, drug abuse, or mental illness. The participants were recruited from 13 preschools in three districts with highest numbers of new immigrant families from mainland China with children aged five years or under $(\mathrm{n}=$ $120)$, and two social services centres $(n=21)$ from two other districts. The participants from preschools were randomized into intervention (IP) and comparison group (C). The randomization was at the preschool level and there were seven preschools in the intervention group $(\mathrm{n}=66)$, and six preschools ( $\mathrm{n}$ $=54$ ) in the comparison group. All participants in the social services centres (IS) were assigned to the intervention group. The demographic characteristics of the participants are in Table 1.

\section{Measures}

\section{Child Measures}

Wechsler Preschool and Primary Scale of Intelligencerevised edition (WPPSI-R) (Wechsler, 2000) - this is an individually administered intelligence scale for children aged 3 years to 7 years 3 months. The Chinese version was published in 2000 .

The Peabody Picture Vocabulary Test Revised (Form L) (PPVT-R; Dunn \& Dunn, Taiwanese Version, 1994) - this Chinese adaptation of the original American test is a nonverbal test designed to evaluate the receptive knowledge of vocabulary of children 3 to 12 years of age.

\section{Parent Measures}

Eyberg Child Behaviour Inventory (ECBI) (Eyberg \& Ross, 1978) - this is a 36-item multidimensional measure of parental perception of disruptive behaviour in children and incorporates two scores, intensity score and problem score. The Chinese version of the inventory has been validated by Leung, Chan, Pang and Cheng (2003).

Parenting Stress Index (PSI) (Lam, 1999) - this is a 36-item questionnaire on issues related to parenting stress. The Chinese version of the scale has been validated by Lam (1999).

General Self Efficacy Scale (Schwarzer, 1993) - this scale consists of 10 items on a sense of personal competence in efficiently dealing with various stressful situations measured on a 4-point Likert scale ranging from "Not at all true" (1) to "Exactly true" (4). A validated Chinese version is available (Zhang \& Schwarzer, 1995).

Duke-UNC Functional Social Support Questionnaire (Broadhead, Gehlbach, de Gruy \& Kaplan, 1988) - this is an 8-item questionnaire on perceived social support in various areas. The questionnaire has been translated into Chinese using back translation. It has been used with Chinese immigrants in Hong Kong (Leung et al., 2007) and the reliability (Cronbach's Alpha) was .84.

Demographic information-parents are requested to supply basic demographic information.

\section{Qualitative Data}

Focus group discussion guides and semi-structured interview guides were used for focus group discussions with participating parents and individual interviews with preschool principals and social services centre supervisors.

\section{Intervention}

The intervention arm participants (IP and IS) participated in the HOPE program, a 30-session program. The sessions were 
Table 1.

Demographic characteristics of participants.

\begin{tabular}{|c|c|c|c|c|}
\hline & $\begin{array}{l}\text { Preschool (IP) } \\
\quad(\mathrm{n}=66)\end{array}$ & $\begin{array}{c}\text { Social Services } \\
\text { Centres (IS) }(\mathrm{n}=21)\end{array}$ & Comparison $(\mathrm{C})(\mathrm{n}=54)$ & Significance \\
\hline Child age & $4.64(0.70)$ & $4.37(0.64)$ & $4.58(0.58)$ & $\mathrm{F}(2,138)=1.38, p=.256$ \\
\hline Child length of residence in Hong Kong & $3.90(1.29)$ & $3.63(1.48)$ & $3.82(1.44)$ & $\mathrm{F}(2,138)=0.31, p=.738$ \\
\hline Mother age & $32.48(3.79)$ & $30.60(3.69)$ & $33.23(5.24)$ & $\mathrm{F}(2,135)=2.60, p=.078$ \\
\hline Mother length of residence in Hong Kong & $2.92(2.25)$ & $3.08(2.90)$ & $3.28(2.72)$ & $\mathrm{F}(2,134)=0.30, p=.744$ \\
\hline Father age & $38.77(6.04)$ & $39.45(8.60)$ & $40.73(8.01)$ & $\mathrm{F}(2,133)=1.06, p=.348$ \\
\hline Father length of residence in Hong Kong & $27.43(15.22)$ & $31.05(13.97)$ & $30.12(14.97)$ & $\mathrm{F}(2,131)=0.68, p=.509$ \\
\hline Number of children & $1.71(0.65)$ & $1.35(0.49)$ & $1.73(0.60)$ & $\mathrm{F}(2,135)=3.16, p=.046$ \\
\hline Child sex (boys) & $33(50.0 \%)$ & $12(57.1 \%)$ & $25(46.3 \%)$ & $\chi^{2}(2)=0.72, p=.698$ \\
\hline Family status: nuclear & $48(72.7 \%)$ & $17(81.0 \%)$ & $29(53.7 \%)$ & \\
\hline Family status: extended & $15(22.7 \%)$ & $0(0 \%)$ & $22(40.7 \%)$ & $\chi^{2}(6)=12.56, p=.051$ \\
\hline Family status: others & $3(4.5 \%)$ & $0(0 \%)$ & $1(1.9 \%)$ & \\
\hline Marital status: married & $63(95.5 \%)$ & $20(95.2 \%)$ & $52(96.3 \%)$ & $\chi^{2}(4)=3.35, p=.502$ \\
\hline Mother education: 9 years or less ${ }^{1}$ & $46(69.7 \%)$ & $13(61.9 \%)$ & $32(59.3 \%)$ & $\chi^{2}(2)=0.87, p=.647$ \\
\hline Father education: 9 years or less ${ }^{1}$ & $37(56.1 \%)$ & $7(33.3 \%)$ & $26(48.1 \%)$ & $\chi^{2}(2)=3.20, p=.202$ \\
\hline Mother employed & $2(3.0 \%)$ & $1(4.8 \%)$ & $0(0 \%)$ & $\chi^{2}(2)=1.91, p=.385$ \\
\hline Father employed & $52(78.8 \%)$ & $14(66.6 \%)$ & $33(61.1 \%)$ & $\chi^{2}(2)=1.98, p=.371$ \\
\hline Household income HK $\$ 19,999$ or below ${ }^{2}$ & $64(97.0 \%)$ & $19(90.5 \%)$ & $44(81.5 \%)$ & $\chi^{2}(2)=3.80, p=.149$ \\
\hline On Social Security & $7(10.6 \%)$ & $1(4.8 \%)$ & $6(11.1 \%)$ & $\chi^{2}(2)=0.71, p=.702$ \\
\hline
\end{tabular}

Note 1: The Hong Kong education system prescribes nine years' compulsory education for all students; Note 2: The median domestic household income was HK\$17,250 (Census and Statistics Department, 2007b).

conducted weekly, with each session lasting for about two hours. The program was conducted by three social workers, with one taking up six groups (five IP and one IS), one taking two IP groups, and one taking one IS group. A manual with lecture script for each session, powerpoint slides, parent handout and parent worksheets was available. Facilitators were trained to adhere strictly to the manual in group delivery.

The participants in the control arm (comparison group) were offered the preschool version of the Universal Parent Education Program. This program was developed by the Education Bureau of the Hong Kong SAR Government for the use of all preschools as a universal parent training program. The program consisted of six sessions on parents' role, self-esteem, parent-child communication, behavior management and child learning. Each session lasted for about two hours and the sessions were conducted over six months, with one session per month. The program was conducted by a health professional with training in parent education.

\section{Procedures}

Invitation letters were sent to all the preschools in the three districts with highest number of Chinese immigrant families with preschool children, inviting them to participate in a parent training program. Upon their consent to participate, preschools were allocated to either the intervention or comparison arm by random assignment. Two social services centres in two other districts were interested in the HOPE program and they recruited participants through their own usual means such as posters and leaflets, or invitation by social workers working in the centres. All participants recruited in the two centres participated in the HOPE program.

Upon signing the consent forms, the parent participants were requested to complete the parent measures prior to the commencement of the program, and upon program completion. The children of the participating parents were assessed on the child measures prior to the commencement of the program, and upon program completion by clinical psychologists or educational psychologists, and educational psychologists-in-training, under the supervision of clinical or educational psychologists. The allocation of assessors to children was random, according to the availability of the assessors during the scheduled times. Assessors were blind to the group membership of the children they assessed. All child assessment was conducted in Cantonese in 
preschools (IP and C groups) or service centres (IS group), usually within one session, with breaks for children where necessary.

At the completion of the program, focus groups were conducted with parents and individual interviews were conducted with preschool principals in the intervention arm, and the supervisors of the social services centres. These focus groups and individual interviews were conducted by two educational psychologists-in-training as part of their course requirements. The interviews and focus group discussions were transcribed verbatim by these two educational psychologists-in-training.

This study was approved by the ethics committee of The Hong Kong Institute of Education, where the first author worked at the commencement of the project.

\section{Data Analysis}

Repeated measures analysis of variance (ANOVA) was used to analyse the data. The between subject variable was organization (IP versus IS versus C) and the dependent variables were child behavior and parenting measures, with two levels (preintervention and post-intervention). The main result of interest was the interaction effect (types of organization $\mathrm{X}$ measures). Analysis was conducted for participants with available data on the variables measured, and by intention-to-treat.

\section{Results}

\section{The Sample}

There was no significant difference between the three groups in terms of parent completion of pre-intervention measures, $\chi^{2}(2)=2.15, p=.342$, post-intervention measures, $\chi^{2}(2)=4.77$, $p=.092$, and child completion of pre-intervention measures, $\chi^{2}(2)=1.22, p=.543$. There was a significant difference in child completion of post-intervention measures, $\chi^{2}(2)=9.65, p$ $=.008$. Fewer participants from the IS group completed the post-intervention measures compared with the IP group and $\mathrm{C}$ group. There was a marginally significant difference between the three groups in terms of percentages of drop-out cases, $\chi^{2}(2)$ $=5.95, p=.051$, with a higher percentage of drop-out cases in the IS group. There was also a significant difference in median attendance rate between the three groups $(p<.001)$. The details are in Table 2.

There were 37 drop-out cases where the participants indicated explicitly that they could not continue with the program, with $14(21.2 \%)$ from the IP group, $13(24.1 \%)$ from the C group and $10(47.6 \%)$ from the IS group. The flow of participants is in Figure 1. For the drop-out cases, the parents were invited to complete the post-intervention questionnaires and the children were invited for the post-intervention assessment. In cases where the parents refused to complete the post-intervention questionnaires or refused to allow their children to be assessed at post-intervention, their pre-intervention scores were used to substitute for their post-intervention scores in the intention-to-treat analysis.

There was no significant difference between the drop-out and non-drop-out cases in terms of pre-intervention parent and child measures or demographic variables, except mother employment status, $\chi^{2}(1)=8.85, p=.003$, and pre-intervention self-efficacy scores, $t(134)=2.13, p=.035$. Three mothers (8.8\%) among the drop-out cases were working while none of the mothers who remained in the program were working. The drop-out participants reported lower pre-intervention self-efficacy scores $(M$ $=22.56, S D=5.68,95 \%$ CIs $[20.58,24.54])$ than those who remained $(M=24.77, S D=5.11,95 \%$ CIs $[23.77,25.78])$.

There was no significant difference between the three groups in terms of pre-intervention measures and demographic variables, except for number of children. Post hoc test (LSD) indicated that the IS group families had fewer children than families in the other two groups. As number of children was not significantly correlated with any of the post-intervention child or parent measures, it was not considered as a confounding factor.

\section{Pair-Wise Analysis}

Parent Outcome Measures. In this section, the analysis was based on participants with complete pre-intervention and post-intervention data on respective parent outcome measures. There was a significant difference for pre-intervention and post-intervention measures, $F(1,112)=15.09, p<.001$, partial eta squared $=.119$, as well as a significant interaction effect (type of organization X measure) for ECBI-intensity, $F(2,112)$ $=3.98, p=.021$, partial eta squared $=.066$. There was a decrease in child behavior problems from pre-intervention to post-intervention among the IP and IS groups, but not the C group. Post hoc test (LSD) indicated that the three groups differed from one another in post-intervention ECBI-intensity scores. For ECBI-problem, there was a significant difference for pre-intervention and post- intervention measures, $F(1,112)$ $=35.63, p<.001$, partial eta squared $=.241$, but the interaction effect (type of organization $\mathrm{X}$ measure) was not significant, $F(2,112)=1.61, p=.205$, partial eta squared $=.028$. For social

Table 2.

Completion of outcome measures and program.

\begin{tabular}{lcccc}
\hline & IP $(\mathrm{n}=66)$ & IS ( $=21)$ & C (n=54) & Total (N=141) \\
\hline Complete pre-intervention parent measures & $63(95.5 \%)$ & $20(95.2 \%)$ & $48(88.9 \%)$ & $131(92.9 \%)$ \\
Complete post-intervention parent measures & $60(90.9 \%)$ & $16(76.2 \%)$ & $42(77.8 \%)$ & $118(83.7 \%)$ \\
Complete pre-intervention child measures & $65(98.5 \%)$ & $21(100 \%)$ & $52(96.3 \%)$ & $138(97.9 \%)$ \\
Complete post-intervention child measures & $62(93.9 \%)$ & $15(71.4 \%)$ & $50(92.6 \%)$ & $127(90.1 \%)$ \\
Remained in program & $52(78.8 \%)$ & $11(52.4 \%)$ & $41(75.9 \%)$ & $104(73.8 \%)$ \\
Median attendance & $89.00 \%$ & $46.00 \%$ & $33.00 \%$ & $83.00 \%$ \\
\hline
\end{tabular}




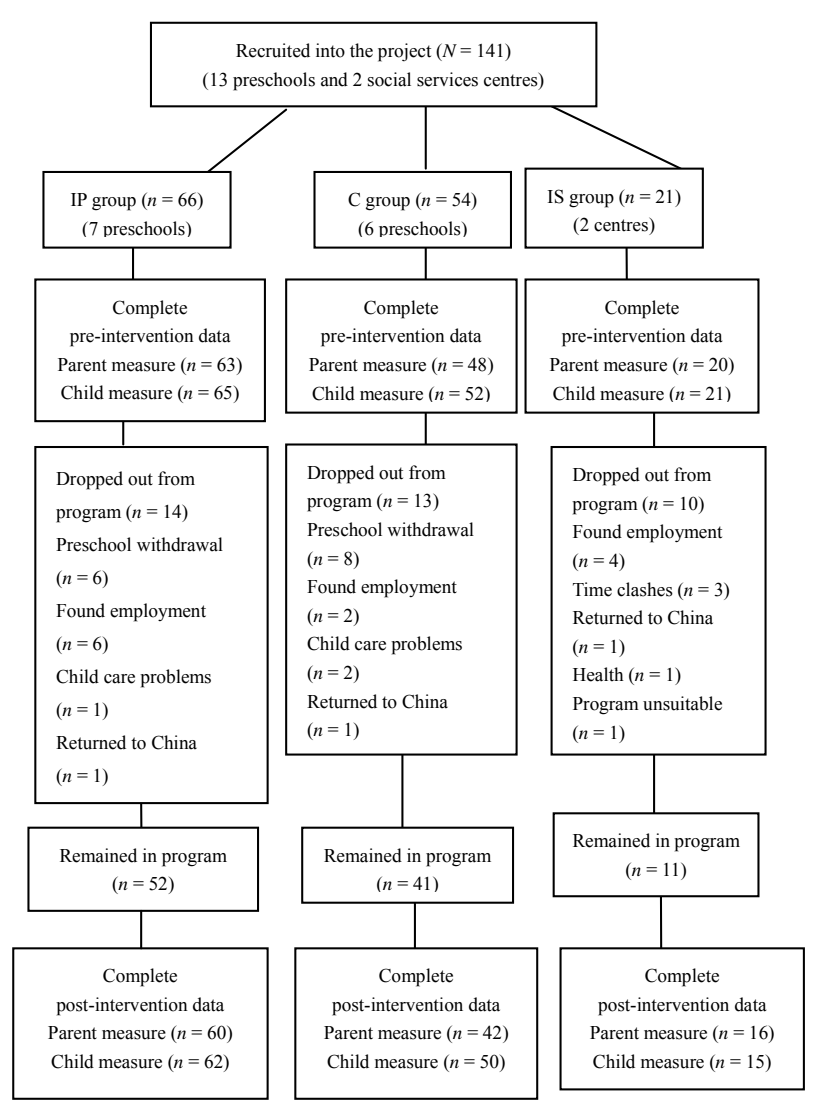

Figure 1.

Flow of participants through each stage of the project.

support, there was a significant difference for pre-intervention and post-intervention measures, $F(1,110)=8.26, p=.005$, partial eta squared $=.070$, and the interaction effect (type of organization $\mathrm{X}$ measure) was also significant, $F(2,110)=4.84, p$ $=.010$, partial eta squared $=.081$. There was an increase in social support in the IP group, but not in the IS group. Post hoc (LSD) test indicated that the IP differed significantly from IS and $\mathrm{C}$ groups. For PSI, there was a significant difference for pre-intervention and post-intervention measures, $F(1,110)=$ 23.08, $p<.001$, partial eta squared $=.173$, and the interaction effect (type of organization $\mathrm{X}$ measure) was also significant, $F(2,110)=3.14, p=.047$, partial eta squared $=.054$. There was a decrease in parenting stress from pre-intervention to post-intervention for IP group but not so in the IS group. However, post hoc test did not indicate any differences between groups. For self-efficacy, there was a significant difference for pre-intervention and post-intervention measures, $F(1,112)=$ $4.288, p=.041$, partial eta squared $=.037$, but the interaction effect (type of organization $\mathrm{X}$ measure) for self-efficacy was not significant, $F(2,112)=0.55, p=.581$, partial eta squared $=.010$. The details are in Table 3 .

Child Outcome Measures. In this section, the analysis was based on participants with complete pre-intervention and postintervention data on respective child outcome measures. For Verbal IQ, there was a significant difference from pre-intervention to post-intervention, $F(1,122)=17.90, p<.001$, partial eta squared $=.128$, but no significant interaction (group $\mathrm{X}$ measure) effect, $F(2,122)=0.65, p=.526$, partial eta squared
$=.010$. For Performance IQ, there was a significant difference from pre-intervention to post-intervention, $F(1,122)=22.94, p$ $<.001$, partial eta squared $=.158$, but no significant interaction (group X measure) effect, $F(2,122)=0.44, p=.644$, partial eta squared $=.007$. For Full Scale IQ, there was a significant difference from pre-intervention to post-intervention, $F(1,122)=$ $32.07, p<.001$, partial eta squared $=.208$, but no significant interaction (group X measure) effect, $F(2,122)=0.38, p=.684$, partial eta squared $=.006$. For PPVT, there was no significant difference from pre-intervention to post-intervention, $F(1,128)$ $=0.13, p=.717$, partial eta squared $=.001$, and the interaction effect was not significant, $F(2,128)=1.19, p=.307$, partial eta squared $=.018$. The details are in Table 3 .

\section{Intention-to-Treat Analysis}

In this section, the analysis was based on intention-to-treat. For participants with missing post-intervention data, their pre-intervention data was used as substitute. This approach is commonly used in studies on the evaluation of parent training programs (e.g. Hutchings et al. 2007; Sanders, Prior \& Ralph, 2009).

Parent Outcome Measures. There was a significant difference for pre-intervention and post-intervention measures, $F(1,133)=14.85, p<.001$, partial eta squared $=.100$, and a significant interaction effect (type of organization $\mathrm{X}$ measure) for ECBI-intensity, $F(2,133)=4.12, p=.018$, partial eta squared $=.058$. For ECBI-problem, there was a significant difference for pre-intervention and post-intervention measures, $F(1,133)=34.19, p<.001$, partial eta squared $=.205$, but the interaction effect (type of organization $\mathrm{X}$ measure) was not significant, $F(2,133)=2.01, p=.138$, partial eta squared $=.029$. For social support, there was a significant difference for pre-intervention and post-intervention measures, $F(1,130)=$ $9.64, p=.002$, partial eta squared $=.069$, and the interaction effect (type of organization $\mathrm{X}$ measure) was also significant, $F(2,130)=5.98, p=.003$, partial eta squared $=.084$. There was a significant difference for pre-intervention and post-intervention PSI measures, $F(1,130)=24.26, p<.001$, partial eta squared $=.157$, and the interaction effect (type of organization $\mathrm{X}$ measure) for PSI was also significant, $F(2,130)=4.42, p$ $=.014$, partial eta squared $=.064$. For self-efficacy, there was a significant difference for pre-intervention and post-intervention measures, $F(1,133)=4.03, p=.047$, partial eta squared $=.029$, but the interaction effect (type of organization $\mathrm{X}$ measure) was not significant, $F(2,133)=0.43, p=.654$, partial eta squared $=.006$.

Child Outcome Measures. For Verbal IQ, there was a significant difference from preintervention to post-intervention, $F(1,135)=16.98, p<.001$, partial eta squared $=.112$, but there was no significant interaction (group $X$ measure) effect, $F$ $(2,135)=0.26, p=.775$, partial eta squared $=.004$. For Performance IQ, there was a significant difference from pre-intervention to post-intervention, $F(1,135)=22.42, p<.001$, partial eta squared $=.142$, but there was no interaction (group X measure) effect, $F(2,135)=0.31, p=.734$, partial eta squared $=.005$. For Full Scale IQ, there was a significant difference from pre-intervention to post-intervention, $F(1,135)=30.76, p$ $<.001$, partial eta squared $=.186$, but there was no significant interaction (group X measure) effect, $F(2,135)=0.03, p=.968$, partial eta squared $=.000$. For PPVT, there was no significant difference from pre-intervention to post-intervention, $F(1,136)$ 
Table 3.

Pre, and post-intervention scores with $95 \%$ confidence interval and reliability estimates ( $\alpha$ ) (where appropriate) for pair wise comparison.

\begin{tabular}{|c|c|c|c|c|c|c|c|}
\hline & $\mathrm{IP}(\mathrm{n}=66)$ & & IS $(n=21)$ & & $\mathrm{C}(\mathrm{n}=54)$ & & Total \\
\hline & Mean $(95 \% \mathrm{CI})$ & $\alpha$ & Mean $(95 \% \mathrm{CI})$ & $\alpha$ & Mean $(95 \% \mathrm{CI})$ & $\alpha$ & Sig \\
\hline Pre ECBI-Intensity & $\begin{array}{c}119.62[113.22,122.03] \\
(\mathrm{n}=66)\end{array}$ & .93 & $\begin{array}{c}111.80[100.07,123.53] \\
(\mathrm{n}=20)\end{array}$ & .91 & $117.60[110.99,124.21](\mathrm{n}=50)$ & .92 & $\begin{array}{c}\mathrm{F}(2,133)=0.76 \\
p=.471\end{array}$ \\
\hline Post ECBI-Intensity & $\begin{array}{c}109.45[104.55,114.35] \\
(\mathrm{n}=60)\end{array}$ & .92 & $\begin{array}{c}95.94[84.58,107.29] \\
(\mathrm{n}=16)\end{array}$ & .92 & $118.21[111.17,125.26](n=42)$ & .93 & $\begin{array}{c}\mathrm{F}(2,115)=6.93, \\
\quad p=.001\end{array}$ \\
\hline $\begin{array}{l}\text { Pre ECBI- } \\
\text { Problem }\end{array}$ & $\begin{array}{c}10.95[8.91,13.00] \\
\quad(\mathrm{n}=66)\end{array}$ & .92 & $\begin{array}{c}9.45[5.63,13.27] \\
\quad(\mathrm{n}=20)\end{array}$ & .93 & $11.56[9.25,13.87](\mathrm{n}=50)$ & .91 & $\begin{array}{c}\mathrm{F}(2,133)=0.47 \\
p=.626\end{array}$ \\
\hline $\begin{array}{l}\text { Post ECBI- } \\
\text { Problem }\end{array}$ & $\begin{array}{c}5.30[3.34,7.26] \\
(\mathrm{n}=60)\end{array}$ & .95 & $\begin{array}{c}3.38[1.24,5.51) \\
\quad(n=16)\end{array}$ & .84 & $8.83[6.56,11.10](\mathrm{n}=42)$ & .91 & $\begin{array}{c}\mathrm{F}(2,115)=4.61, \\
p=.012\end{array}$ \\
\hline Pre PSI & $\begin{array}{c}99.55[95.49,103.60] \\
(\mathrm{n}=64)\end{array}$ & .90 & $\begin{array}{c}96.20[89.26,103.14] \\
(\mathrm{n}=20)\end{array}$ & .87 & $97.41[92.57,102.24](\mathrm{n}=49)$ & .91 & $\begin{array}{c}\mathrm{F}(2,130)=0.43 \\
p=.653\end{array}$ \\
\hline Post PSI & $\begin{array}{c}87.63[84.19,91.08] \\
(\mathrm{n}=60)\end{array}$ & .89 & $\begin{array}{c}91.63[84.74,98.51] \\
(\mathrm{n}=16)\end{array}$ & .81 & $91.69[87.08,96.30](\mathrm{n}=42)$ & .89 & $\begin{array}{c}\mathrm{F}(2,115)=1.26 \\
p=.288\end{array}$ \\
\hline Pre Social Support & $\begin{array}{c}25.84[24.30,27.39] \\
(\mathrm{n}=64)\end{array}$ & .82 & $\begin{array}{c}24.25[20.56,27.94] \\
(\mathrm{n}=20)\end{array}$ & .84 & $25.71[23.86,27.57](\mathrm{n}=49)$ & .85 & $\begin{array}{c}\mathrm{F}(2,130) 0.47 \\
p=.624\end{array}$ \\
\hline Post Social support & $\begin{array}{c}30.13[28.69,31.58] \\
(\mathrm{n}=60)\end{array}$ & .90 & $\begin{array}{c}25.94[21.58,30.29] \\
(\mathrm{n}=16)\end{array}$ & .88 & $27.33[25.50,29.16](\mathrm{n}=42)$ & .79 & $\begin{array}{c}\mathrm{F}(2,115)=4.34 \\
p=.015\end{array}$ \\
\hline Pre Self-efficacy & $\begin{array}{c}24.47[23.35,25.59] \\
(\mathrm{n}=66)\end{array}$ & .83 & $\begin{array}{c}22.45[19.71,25.19] \\
(\mathrm{n}=20)\end{array}$ & .85 & $24.60[22.90,26.30](\mathrm{n}=50)$ & .90 & $\begin{array}{c}\mathrm{F}(2,133)=1.31 \\
p=.273\end{array}$ \\
\hline Post Self-efficacy & $\begin{array}{c}25.28[23.90,26.67] \\
(\mathrm{n}=60)\end{array}$ & .87 & $\begin{array}{c}23.31[20.14,26.48] \\
(\mathrm{n}=16)\end{array}$ & .87 & $23.93[22.09,25.77](\mathrm{n}=42)$ & .90 & $\begin{array}{c}\mathrm{F}(2,115)=1.15 \\
p=.321\end{array}$ \\
\hline Pre Verbal IQ & $\begin{array}{c}100.38[96.99,103.78] \\
(\mathrm{n}=65)\end{array}$ & NA & $\begin{array}{c}101.86[97.19,106.53] \\
(\mathrm{n}=21)\end{array}$ & NA & $96.40[93.40,99.41](\mathrm{n}=52)$ & NA & $\begin{array}{c}\mathrm{F}(2,133)=2.17 \\
p=.119\end{array}$ \\
\hline Post Verbal IQ & $\begin{array}{c}104.03[100.92,107.15] \\
(\mathrm{n}=62)\end{array}$ & NA & $\begin{array}{c}109.13[102.48,115.79] \\
(\mathrm{n}=15)\end{array}$ & NA & $101.68[98.98,104.37](\mathrm{n}=50)$ & NA & $\begin{array}{c}\mathrm{F}(2,124)=2.60 \\
p=.078\end{array}$ \\
\hline Pre Performance IQ & $\begin{array}{c}101.92[98.18,105.67] \\
(\mathrm{n}=66)\end{array}$ & NA & $\begin{array}{c}106.00[100.44,111.56] \\
(\mathrm{n}=21)\end{array}$ & NA & $105.00[100.68,109.32](\mathrm{n}=52)$ & NA & $\begin{array}{c}\mathrm{F}(2,136)=0.91 \\
p=.404\end{array}$ \\
\hline Post Performance IQ & $\begin{array}{c}108.32[104.372,112.28] \\
(\mathrm{n}=62)\end{array}$ & NA & $\begin{array}{c}114.27[107.05,121.48] \\
(\mathrm{n}=15)\end{array}$ & NA & $110.64[106.877,114.41](\mathrm{n}=50)$ & NA & $\begin{array}{c}\mathrm{F}(2,124)=1.12 \\
\quad p=.328\end{array}$ \\
\hline Pre Full Scale IQ & $\begin{array}{c}100.74[97.22,104.25] \\
(\mathrm{n}=65)\end{array}$ & NA & $\begin{array}{c}104.29[99.06,109.51] \\
(\mathrm{n}=21)\end{array}$ & NA & $100.37[96.80,103.93](\mathrm{n}=52)$ & NA & $\begin{array}{c}\mathrm{F}(2,135)=0.71, \\
p=.496\end{array}$ \\
\hline Post Full Scale IQ & $\begin{array}{c}106.81[103.47,110.14] \\
(\mathrm{n}=62)\end{array}$ & NA & $\begin{array}{c}113.07[106.22,119.91] \\
(\mathrm{n}=15)\end{array}$ & NA & $106.78[103.77,109.79](\mathrm{n}=50)$ & NA & $\begin{array}{c}\mathrm{F}(2,124)=1.78 \\
p=.173\end{array}$ \\
\hline Pre PPVT & $\begin{array}{c}111.05[106.99,115.10] \\
(\mathrm{n}=66)\end{array}$ & NA & $\begin{array}{c}109.38[103.54,115.22] \\
(\mathrm{n}=21)\end{array}$ & NA & $108.81[106.12,111.50](n=53)$ & NA & $\begin{array}{c}\mathrm{F}(2,137)=0.41 \\
p=.665\end{array}$ \\
\hline Post PPVT & $\begin{array}{c}107.40[104.24,110.56] \\
(\mathrm{n}=63)\end{array}$ & NA & $\begin{array}{c}111.26[105.59,116.94] \\
(\mathrm{n}=19)\end{array}$ & NA & $108.82[104.77,112.87](\mathrm{n}=50)$ & NA & $\begin{array}{c}\mathrm{F}(2,129)=0.66 \\
p=.519\end{array}$ \\
\hline
\end{tabular}


$=0.17, p=.685$, partial eta squared $=.001$, and the interaction effect was not significant, $F(2,136)=1.23, p=.296$, partial eta squared $=.018$.

\section{Qualitative Information}

As the main difference between the preschool group and the social services group was the context or setting where the program was conducted, rather than the program content or activities, the focus of the discussion in this section was on the contextual factors influencing the program. The information was mainly derived from the interviews with the preschool principals and social services centre supervisors. They were the key people who "created" the context for the delivery and implementation of the program.

When the preschool principals and the social services centre supervisors were asked about their perceived objectives of the program, there were subtle differences. Though both stated that the program was to equip new immigrant parents with parenting skills, the preschool principals (educators) stated explicitly that the program could help the children and their learning whereas the centre supervisors (social workers) emphasized that the program could help parents learn how to manage their children. One might argue that the centre supervisors focused more on the parents whereas the preschool principals focused more on children.

In terms of their own roles, both centre supervisors and preschool principals claimed that they played a coordinating role. The centre supervisors further maintained that they were interested in wider issues such as the effectiveness of the program and community liaison. The preschool principals focused on their roles in the day-to-day running of the program.

Both centre supervisors and preschool principals reported positive changes in child learning, behavior, parenting and parent-child relationship. Being more child-centred in their service and set up, the preschool principals reported their direct firsthand observation of changes in children, such as their learning, or behavior. With a focus on both youth and parents, the centre supervisors gathered such information from the report of the parents.

One of the purposes of the group sessions was to provide a platform to facilitate new immigrant parents to build up their social network. Both preschool principals and social services centre supervisors reported their observations of increased parent social interaction and support.

With respect to the benefits of the program to the preschools and social services centres, both parties could list benefits. However, the focus was quite different. The centre supervisors were more adult-focused and elaborated on the participants' relationship with the centre and emphasized that the social services centre was a resource to support parents. The preschool principals were more child-focused and discussed the benefits in terms of benefit for the children, as well as changes in parent-school relationship.

Finally, both parties were invited to comment on the delivery of the program within their setting. Both could identify some specific benefits, though one of the centre supervisors did identify some difficulties in relation to recruitment, which, in a way, could be made easier in the preschool setting.

It is understandable that there might be a problem with stigma for using social services centres. For many parents, there is no perceived requirement for service use, or regular/intensive attendance. Social services centres are likely to assess success by the clients' help-seeking willingness, and connection with centre is an important indicator. For preschools, education is perceived by parents as essential and so the motivation is different. Parents probably accept regular and intensive attendance to school as essential and normal.

\section{Discussion}

The quantitative results indicated that there were significant differences in post-intervention social support, favoring the preschools relative to social services centres. These outcomes were parent outcomes. Both preschools and social services centres were effective in producing decrease in child behavior problems (ECBI-intensity). There was a marginal difference in drop-out rate with a higher percentage of drop-out cases in social services centres (IS group).

There was a difference between the preschools and social service centres in terms of perceived target clients for the program. For the preschools, the target clients were the school children. It was obvious that preschools joined the program because they considered that the program could benefit the children as an early intervention program, through empowering and equipping the parents, and they could observe changes in the children directly. In the end, they thought the program could help the school because it helped the children. For the social services centres, the focus shifted to adults and they hoped to provide support to the parents and to build up their connections with the centre. The supervisors thought that the program could help the parents, and this could also help to improve the relationship between the parents and the centre. This is consistent with Gross and Grady (2006) who claimed that it was important for the organization to perceive the goal of the parenting program as consistent with the goals of the organization.

One possible advantage of the preschool is that it is a familiar setting for the new immigrant parents. This is a facilitating factor. Furthermore, the preschools are more likely to be in a location convenient to the parents and this is another incentive. It is also possible that being invited by the preschool principal to attend a school program is less stigmatizing than attending a parenting program in a social services centre, which might still be seen as a place for people with problems. This is, to some extent, substantiated by the quantitative findings where the drop-out rate was lower among preschool participants. On the other hand, there could be creative collaboration between social services centres and preschools. Social workers could deliver the parenting program in preschools and this would provide additional resources for preschools to realize their goals of promoting child development. This can be regarded as a creative solution to the resource problems in Hong Kong preschools (Rao \& Li, 2009). Through the program, social workers can also introduce the parents to the services of their social services centres and to encourage the parents to make use of the centre resources, thus building up the connection between the parents and the centres. Knowledge/awareness of available services and perceived accessibility of service are important considerations (Leong \& Lau, 2001) for help-seeking behaviour.

According to Gross and Grady (2006), the support of the administration is important to maintain participation and motivation. The preschools could see that the program could enhance parent-school relationship, and is in line with Epstein's model of home-school collaboration (Epstein, 2001). Both the 
teachers and the program consistently reinforced the parenting skills and this also led to better home-school co-operation and communication. Furthermore, the program and the teachers could complement and reinforce each other in equipping and supporting the parents to promote the development of the children. The improved relationship with the preschool, the support and encouragement of preschool principals and teachers might be another incentive for attending the program and a possible reason for decrease in parenting stress. On the other hand, social services centres also see the program as an important means to engage parents and to build up a relationship between the parents and the centre. A social services centre is also equipped with an array of professional resources which can support parents with various personal and family needs. There might be parents with personal or family problems or financial problems, and social services centres are in a much better position to support these parents. They have trained social workers with expertise and knowledge in these areas. Shriver and Allen (2006) have pointed out that intensive individual treatment protocols might not be viable in preschools.

The quantitative results indicated a significant difference in post-intervention social support between the two groups. In preschools, the program provided a platform for parents to further develop their friendship as they might have known each other before the program. For the social services centre, the parents might be strangers to each other before the program and more time might be needed to build up a supportive and trusting relationship. On the other hand, social services centres with flexible opening hours can provide a venue for parents to gather together, both formally and informally, whereas preschools might be more limited by space or opening hours.

\section{Limitations}

First, this study may somehow be regarded as a post hoc study as we did not set out to investigate the issue of contextual influence on program effectiveness. However, the results do provide useful insight for practice, and useful research questions for future studies. Second, complete randomization was not used in group allocation in the sense that all social services centres were offered the HOPE program, and there might be subtle differences in the participants which could be potential confounders. However, there was no significant difference between the three groups (IP and C preschools and social services centres) in most demographic characteristics or pre-intervention scores. Third, the child measures were tests standardized with Chinese children in Taiwan, rather than Hong Kong. The researchers were fully aware of the limitations of these tests but at the time of the study, there was no cognitive test for preschool children normed for Hong Kong Chinese children. Fourth, some parents dropped out from the study due to various reasons, including perceived inappropriateness of the program, child care and employment issues. There were more working mothers among the drop-out cases and their pre-intervention self-efficacy scores were lower. There was a marginally statistically significant difference in drop-out among the three groups, with more drop-out cases in the IS group, though the drop-out in the IP group was the lowest among the three groups. These might have implications for the external validity of the program, as we could not generalize the results to the drop-out participants. For internal validity, we have conducted intention-to-treat to include the data of the drop-out cases in the analysis, to deal with differential loss to follow-up. Finally, there was no independent validation of treatment fidelity, although a detailed manual was available and facilitators were instructed to adhere closely to the manual.

\section{Implications for Services}

While preschools and social services centres are possible settings where early intervention programs such as parent training can be offered, they have different strengths which should be fully utilized by policy makers and service planners. In the Hong Kong situation, preschools may be limited by funding resources, and social services centres might have service quota to meet. This creates a unique opportunity for the two to collaborate to reach the target parents for early intervention programs. However, it is also important to understand the unique community profile, location and accessibility of the facilities, and use different promotion strategies to attract parents. The different funding and services arrangements of preschools and social services centres and their constraints must also be taken into consideration. Preschools and social services centres may need to allow for additional input such as adding social functions to enhance social networking; or casework support to parents with psychosocial difficulties.

For tertiary institutions collaborating with preschools or social services centres in implementing or evaluating early intervention programs such as parent training programs, briefing to the principals and centre supervisors should also be tailor-made to ensure they fully understand the potential contributions of the program. Engagement of the staff is also important so they do not perceive the program as an additional burden or a means to fulfill the quota set by the government or sponsor. The research/program mindset of the personnel is also important as this will affect their devotion to the program.

\section{Acknowledgements}

This study is supported by a Public Policy Research Fund, Research Grants Council, Hong Kong. The authors gratefully acknowledge the participation of the parents and their permission for us to report the results of the program in this article.

\section{REFERENCES}

Barlow, J., \& Parsons, J. (2005). Group-based parent-training programmes for improving emotional and behavioural adjustment in 0-3 year old children. Campbell Systematic Reviews, 3.

Broadhead, W. E., Gehlbach, S. H., De Gruy, F. V., \& Kaplan, B. H. (1988). The Duke-UNC functional social support questionnaire: Measurement of social support in family medicine patients. Medical Care, 26, 709-723. doi:10.1097/00005650-198807000-00006

Census and Statistics Department (2007a). 2006 Population by-census thematic report: Persons from the mainland having resided in Hong Kong for less than 7 years. Hong Kong: Hong Kong SAR Government Census and Statistics Department.

Census and Statistics Department (2007b). 2006 Population by-census thematic report: Household income distribution in Hong Kong. Hong Kong: Hong Kong SAR Government Census and Statistics Department.

Cunningham, C. E., Bremner, R. B., \& Boyle, M. (1995). Large group community-based parenting programs for families of preschoolers at risk for disruptive behavior disorders: Utilization, cost effectiveness, and outcome. Journal of Child Psychology and Psychiatry, 36, 1141 1159. doi:10.1111/j.1469-7610.1995.tb01362.x 
Dunn, L. M., \& Dunn, L. M. (1994). The Peabody Picture Vocabulary Test Revised (Form L) (PPVT-R; Taiwanese Version). Taipei: The Psychological Publishing Co. Ltd.

Epstein, J. L. (2001). School, family and community partnerships: Preparing educators and improving schools. Oxford: Westview Press.

Eyberg, S. M., \& Ross, A. W. (1978). Assessment of child behaviour problems: The validation of a new inventory. Journal of Clinical Psychology, 16, 113-116.

Gross, D., \& Grady, J. (2002). Group-based parent training for preventing mental health disorders in children. Issues in Mental Health Nursing, 23, 367-384. doi:10.1080/01612840290052578

Hutchings, J., Bywater, T., Daley, D., Gardner, F., Whitaker, C., Jones, K., Eames, C., \& Edwards, R. T. (2007). Parenting intervention in Sure Start services for children at risk of developing conduct disorder: Pragmatic randomized controlled trial. BMJ, 334, 678. doi:10.1136/bmj.39126.620799.55

Kohl, P. L., Schurer, J., \& Bellamy, J. L. (2009). The state of parent training: Program offerings and empirical support. Families in Society, 90, 248-254.

Lam, D. (1999). Parenting stress and anger: The Hong Kong experience. Child and Family Social Work, 4, 337-346. doi:10.1046/j.1365-2206.1999.00133.x

Leong, F. T. L., \& Lau, A. S. L. (2001). Barriers to providing effective mental health services to Asian Americans. Mental Health Services Research, 3, 201-214. doi:10.1023/A:1013177014788

Leung, C. M., Chan, S. C. M., Pang, R. C. Y., \& Cheng, W. K. C. (2003). Validation of the Chinese version of the eyberg child behaviour inventory for use in Hong Kong. Wanchai, Hong Kong: Education and Manpower Bureau.

Leung, C., Ip, F., Tso, K., \& Leung, S. (2003). Parenting programme in the Family Health Service. Public Health \& Epidemiology Bulletin, $12,49-53$.
Leung, C., Leung, S. S. L., \& Chan, R. (2007). The adaptation of mainland Chinese immigrant parents of preschool children in Hong Kong. E-Journal of Applied Psychology, 3, 43-57.

Leung, C., Tsang, S., \& Dean, S. (2010). Evaluation of a program to educate disadvantaged parents to enhance child learning. Research on Social Work Practice, 20, 591-599. doi: $10.1177 / 1049731510362224$

Leung, C., Tsang, S., \& Dean, S. (2011). Outcome evaluation of the Hands-On Parent Empowerment (HOPE) Program. Research on Social Work Practice.

Leung, C., Tsang, S., Dean, S., \& Chow, P. (2009). Development and pilot evaluation of the "Hands on Parent Empowerment" (HOPE) project-A parent education programme to establish socially disadvantaged parents as facilitators of preschool children's learning. Journal of Children's Services, 4, 21-32.

Lo, K. T., Wan, A., \& Chung, L. (1999). A survey study on the psychological adaptation of newly arrived students from mainland China. Hong Kong: Aberdeen Kai-Fong Welfare Association Social Service Centre.

Rao, N., \& Li, H. (2009). Quality matters: Early childhood education policy in Hong Kong. Early Child Development and Care, 179, 233245. doi: $10.1080 / 03004430601078644$

Reyno, S. M., \& McGrath, P. J. (2006). Predictors of parent training efficacy for child externalizing behavior problem-A meta-analytic review. Journal of Child Psychology and Psychiatry, 47, 99-111. doi:10.1111/j.1469-7610.2005.01544.x

Sanders, M. R., Prior, J., \& Ralph, A. (2009). An evaluation of a brief universal seminar series on positive parenting: A feasibility study. Journal of Children's Services, 4, 4-20.

Schwarzer, R. (1993). Measurement of perceived self-efficacy: Psychometric scales for cross-cultural research. Berlin: Zentrale Universitats Druckerei der FU Berlin. 